\title{
E-Readiness Assessment for Ministries of Nepal for Implementation of e-government
}

\author{
Abhijit Gupta ${ }^{1}$, Subarna Shakya ${ }^{2}$ and Shreedhar Marasini ${ }^{3}$ \\ ${ }^{1,3}$ Department of Computer Science and Engineering, Singhania University, Rajasthan, India \\ ${ }^{2}$ Department of Electronics and Computer Engineering, Central Campus, Institute of Engineering, Tribhuvan \\ University, Nepal
}

\begin{abstract}
Information and communication technology (ICT) can make rapid changes in government processes, especially in developing countries. Basis of ICT development is composed of ICT infrastructure, ICT hardware, software \& information system, human resource, ICT Security. ICT strategies and ICT plans should be evaluated to align with organization visions and missions in order to achieve effective use of ICT in their businesses.

This study carries out a framework to check the e-readiness of the 5 ministries of Nepal. This study will identify the status of the ministries to obtain benefits which raises from information and communication technologies. It will help to assist government of Nepal to gauge how ready the ministries are to participate in ICT activities such as e-government in terms of six main ICT factors, software and information system, ICT Hardware, Network system, ICT Plans and policies, ICT security and Human Resource.
\end{abstract}

Keywords: e-readiness, e-governance, e-readiness measurement tools, ICT Readiness, e-participation

\section{Introduction}

The significant improvements in communication and information technologies are revolutionizing the way government services are delivered. The initiatives of government agencies and departments to use ICT tools and applications, Internet and mobile devices to support good governance, strengthen existing relationships and build new partnerships within civil society has become the demand of time. It is very important to find the capability to successful adoption, utilization to achieve benefit from ICT for higher quality, cost effective government services and a better relationship between citizens and government.

The potential for eGovernment in developing countries remains largely unexploited, even though ICT is believed to offer considerable potential for the sustainable development of e-Government. Therefore, it is very important to evaluate the capacity of a government organization in terms of e-readiness for implementing eGovernance in country

E-readiness is the measure of the degree to which organization is ready, willing or prepared to obtain benefits which arise from information and communication technologies. This measure is often used to gauge how ready is the organization to participate in electronic activities such as e-governance. E-readiness is a measuring tool, which is used to evaluate the quality of ICT infrastructure at the nation level or in large sized organizations [2]. It can evaluate the ability of consumers, businesses and governments to utilize ICT to their benefit. E-readiness assessments are meant to guide development efforts by providing some suitable tools for comparison and gauging progress [3].

In this light, a study of the e-readiness of the 5 ministries of Nepal is carried out to gain a richer understanding of the situation for implementing e-Governance. ICT Infrastructure, software and information system, Network system, ICT plans and policies, ICT security and Human Resource are the cornerstones for the development of ICT in any organization. Considering these six factors, e-readiness for ministries will be evaluated which will further help in finding out the area where more focus and support is required and which ministry requires to invest more for ICT development.

E-Readiness in this paper is defined as the availability of the necessary physical infrastructure (high bandwidth, reliability and affordable prices); access to information (software and information system); availability of devices required to access information (hardware and network availability and Survivability); 
degree to which the ICT master plans and policies cope with the vision of an organization, the security level adopted by the organization and the human resource to use and manage these resources for the implementation of e-governance.

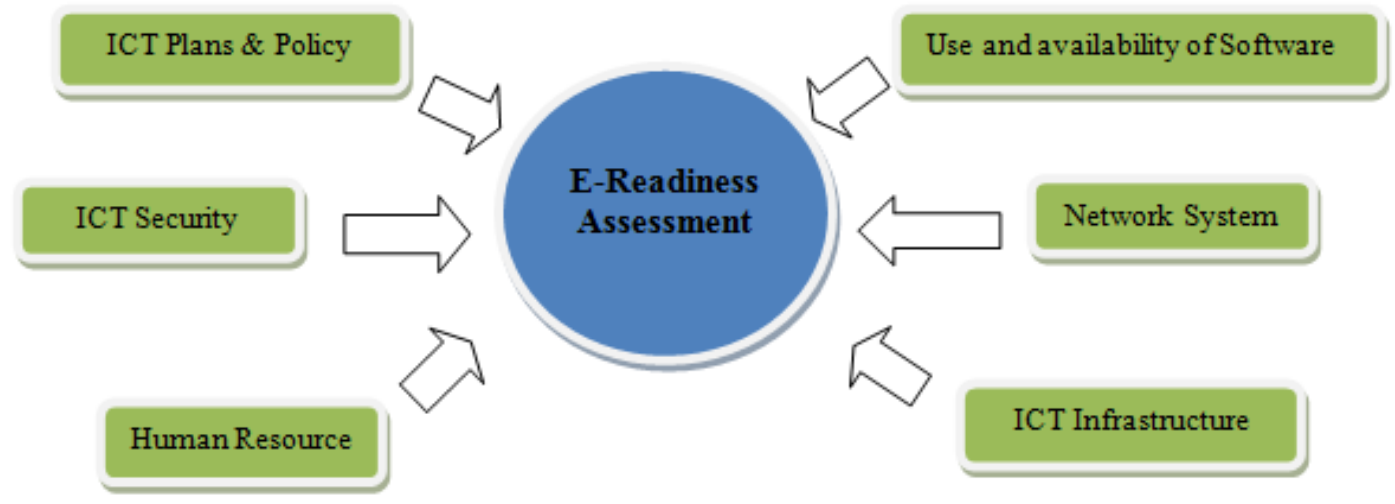

Fig. 1: The proposed e-readiness assessment model

\section{Literature Review}

\subsection{ICT Activities}

ICT activities also known as electronic activities are performed using ICT tools and applications, Internet and mobile devices to support good governance, e-commerce, and build new partnerships within civil society. It ensures higher quality, cost effective services and a better relationship between citizens and government. [1] Many developed countries have taken progressing steps toward the web and ICT use, adding coherence to all local activities on the internet, widening local access and skills, opening up interactive services for local debates and increasing the participation of citizens on promotion and management of the territory.

[1]Researchers agree that ICT has considerable potential to contribute to efficiency gains and cost reductions for private organizations. Furthermore, these benefits constitute a major aspect of e-Government initiatives. (Valentina Dardha Ndou, 2004) [1] Benefits assured by use and application of e-government in developing countries are the same as those in developed countries. The differences between these two groups could result from the fact that many potential benefits of e-Government are not reaped by developing countries as consequence of their limited use of e-Government. The use of ICT for the reorganization of internal administration transactions, communications, and interrelationships and for easy information flow and transfer offers considerable opportunity to increase government capacity.

\subsection{E-Government}

E-Government is a multidimensional and complex concept, which requires a broad definition and understanding. Two organizations have defined e-government and e-governance as:- [1]World Bank, 2001- eGovernment is the government owned or operated system of information and communication technologies that transform relations with citizens, the private sector and/or other government agencies so as to promote citizens' empowerment improve service delivery, strengthen accountability, increase transparency, or improve government efficiency.

[1]UNPA \& ASPA, 2001- e-Governance is the public sector's use of the most innovative information and communication technologies, like the internet, to deliver to all citizens improved services, reliable information and greater knowledge in order to facilitate access to the governing process and encourage deeper citizen participation.

\section{E-readiness for E-government}

2004 survey regarding the success and failure rates of e-Government in developing and transitional countries, Heeks found that more than one-third of initiatives are total failures (e.g the failure of decision support systems in East Africa); further half can be considered to be partial failures (e.g. the partial failure of management information system in Eastern Europe); and roughly one-seventh are successes [1]. 
An empirical web-based study of 15 e-government case studies in 9 developing countries was performed and the result shows that e-government has great potential and opportunities for developing countries for improving their governance and citizen satisfaction level. However, in order to realize the full potential of these applications, government must accommodate certain unique conditions and be able to manage a set of issues, problems and related challenges

\subsection{E-readiness Assessment Models and Tools}

Since more than a decade a number of e-readiness tools have been developed to measure the level of ereadiness of various governmental organizations and the nation.

\subsubsection{Bakry's STOPE Framework}

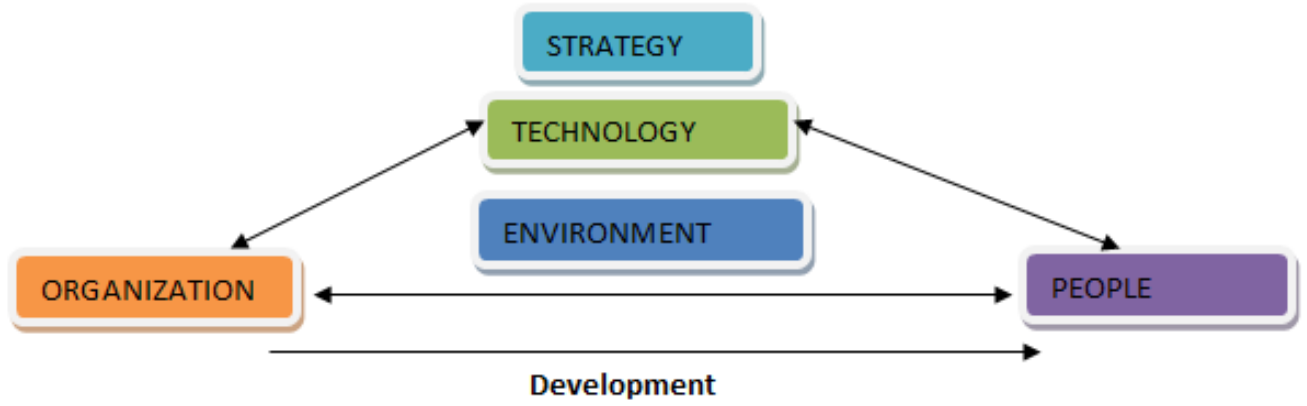

Fig. 2: The basic elements of development: Bakry's STOPE

Bakry considered the "TOP" domains, and added two complementary domains that is "strategy: S", and "environment: E", In his work, concerned with information and communication technology utilization and development,. The result was the STOPE framework, shown in figure III, that was used by Bakry and his colleagues for various studies including studies concerned with: e-business (Bakry, 2001 and Bakry, 2002); egovernment (Bakry, 2004); "enterprise resource planing: ERP" (Bakry, 2005); applications of information services (Jamal Al-Deen, 2000); and security management standards [7]

\section{Research Methodology}

\subsection{Proposed e-Readiness Model}

The framework is based on STOPE framework which has three levels of details. The top level is concerned with main domains. The proposed model replaces the five main domain of STOPE framework with the six main domains: Software and Information system, Hardware and ICT Infrastructure, Network System, Human Resource, ICT Security, ICT plans and Policies which are the main factors of the ICT development for any organization. The second level is concerned with the issues associated with each domain and the third level is concerned with the factors related to each issues.

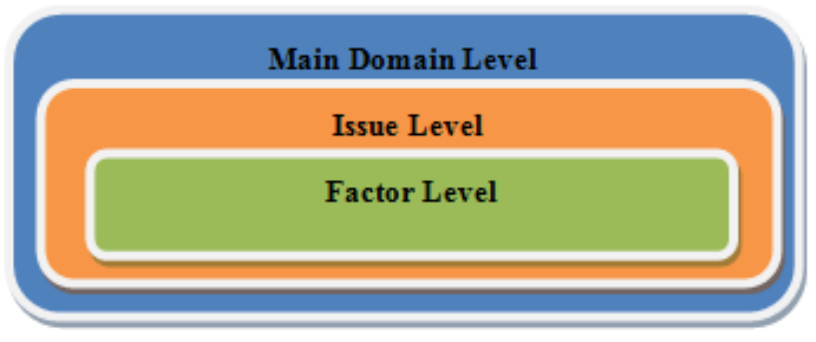

Fig. 3: Framework Levels [7]

\subsubsection{Main Domains}

Question will administer to obtain the strength of all the six domains in a ministry. 
- Network System: It will reflect the interconnection of various pieces of network, network security, survivability and availability. This Domain helps to measure the use as well as capacity of network to share information within and outside the organization with strong security measures.

- Hardware's and ICT infrastructure: This domain helps to measure the ability of the organization to make the optimal use of the available hardware and technologies to deliver services.

- Software/IMS: This Domain helps to measure the capacity of organization to deliver services using different available software and information management system developed by the organization itself.

- ICT Plan and Policies: This domain identifies how well the ICT plan and policies of an organization are and whether they cope with the changing need of an organization or not? This is very important factor for an organization to get benefitted from ICT activities.

- Human Resource: Human resources are the assets of any organization which supports in achieving the goal and objectives of an organization. This domain helps to gauge the ability of the human resource in an organization to support the organization to achieve optimal benefit from the ICT activities.

- ICT Security: This is another one of the important domain that helps to measure the level of ICT security in an organization. It includes the security of information, network, computer, application.

\subsection{Methodology}

This paper applies the e-readiness model to primary data. The employee of the organization is provided with a set of closed questionnaire. The answer is feed into the software, developed using PHP and MySQL. The software computes and shows the result for each of the ministry.

\subsubsection{Criteria for Evaluation}

The e-readiness is evaluated based on both the importance and measures of the factors, issues and domain. Each factor is ranked as shown in table 2.

TABLE I : The grades considered for the evaluation of e-readiness

\begin{tabular}{|c|c|c|c|}
\hline 1 & 2 & 3 & 4 \\
\hline Poor & Average & Good & Very Good \\
\hline
\end{tabular}

Importance is ranked as shown in table 3.

TABLE II : The Importance considered for the evaluation of e-readiness

\begin{tabular}{|c|c|c|c|c|}
\hline 0 & 1 & 2 & 3 & 4 \\
\hline Not Important & Little Important & Average & Important & Very Important \\
\hline
\end{tabular}

The ICT officers at the ministries are allowed to rank the importance of the Domain, Issues associated with that domain and the factors of the issues.

\subsection{Data collection Technique}

Primary data are collected from the various government employees. Five ministries are visited and the questions are presented to the head of the ICT section of that particular ministry.

\subsection{Questionnaires Structure for Data Collection}

Overall 67 questions are asked to the Computer officer/IT Officer/Computer Engineer of the ministry whose job responsibility is to manage the ICT infrastructure of that particular ministry. The survey is limited to 5 ministries. The questionnaires are of following structure.

TABLE III: Question Structure

\begin{tabular}{|c|l|l|}
\hline S.No & Questionnaire Based on & No of Questions \\
\hline 1 & Network System & 7 \\
\hline 2 & Human Resource & 9 \\
\hline 3 & Software /IMS & 10 \\
\hline 4 & Hardware and ICT Infrastructure & 12 \\
\hline 5 & ICT Plans and Policies & 13 \\
\hline 6 & ICT Security & 16 \\
\hline
\end{tabular}




\subsection{Mathematical Model of E-Readiness Level}

The result of this mathematical model refers to e-readiness levels of the participating organizations. The ereadiness levels also provide ICT factor priority for ICT investments and management. For example, if ICT infrastructure factor receives the lowest ICT readiness level, it indicates that ICT infrastructure is in the highest priority for ICT investment and management. The mathematical model can provide an overall level of ICT readiness of each ministry.

\subsubsection{Factor's Measure and Weight Calculation}

The head of the IT Section or IT officer of an organization are allowed to choose one of the option, and each option is given a score from 1-4. That is how we get the measure of the factor. The participating person can rank the factors according to the importance.

After we have got the factor's measure and importance from questionnaire we calculate the factor's weight using the formula.

$$
\text { Factor weight }(w)=\frac{\text { Factor importance }}{\sum_{k=1}^{n} \text { Factor importance }}
$$

We then calculate the relative weighted indicator using the formula,

$$
\text { Relative weight Indicator }=\text { Measure }(M) X \text { Relative Weight }(w)
$$

3.5.2 Issue Measure and Weight: Issue measure is calculated using the formula,

Issue Measure $=\sum_{i=1}^{n} M_{i} X w_{i}$, Where $\mathrm{n}$ is the number of factors for the issue. Like factor's importance each issue importance can be ranked between 1-4. We calculate the issue's weight using the formula.

$$
\text { Issue weight }(w)=\frac{\text { Issue importance }}{\sum_{k=1}^{n} \text { Issue importance }}
$$

We then calculate the relative weighted indicator of Issue using the formula,

\section{Relative weight Indicator $=$ Measure $(M) X$ Relative Weight $(w)$}

3.5.3 Domain Measure and Weight: Domain measure is calculated using the formula, Domain Measure $=\sum_{i=1}^{n} M_{i} X w_{i}$, Where $\mathrm{n}$ is the number of issues for the Domain.

Each domain can be ranked between one to four according to their importance. We calculate the Domain's weight using the formula.

$$
\text { Domain weight }(w)=\frac{\text { Domain importance }}{\sum_{k=1}^{n} \text { Domain importance }}
$$

We then calculate the relative weighted indicator of Domain using the formula,

\section{Relative weight Indicator $=$ Measure $(M) X$ Relative Weight $(w)$}

\subsubsection{E-Readiness Calculation:}

E-readiness is the sum of Relative weight Indicator of the domain.

$$
\text { E-Readiness }=\sum_{i=1}^{n} M_{i} X w_{i}
$$




\section{Result and Discussion}

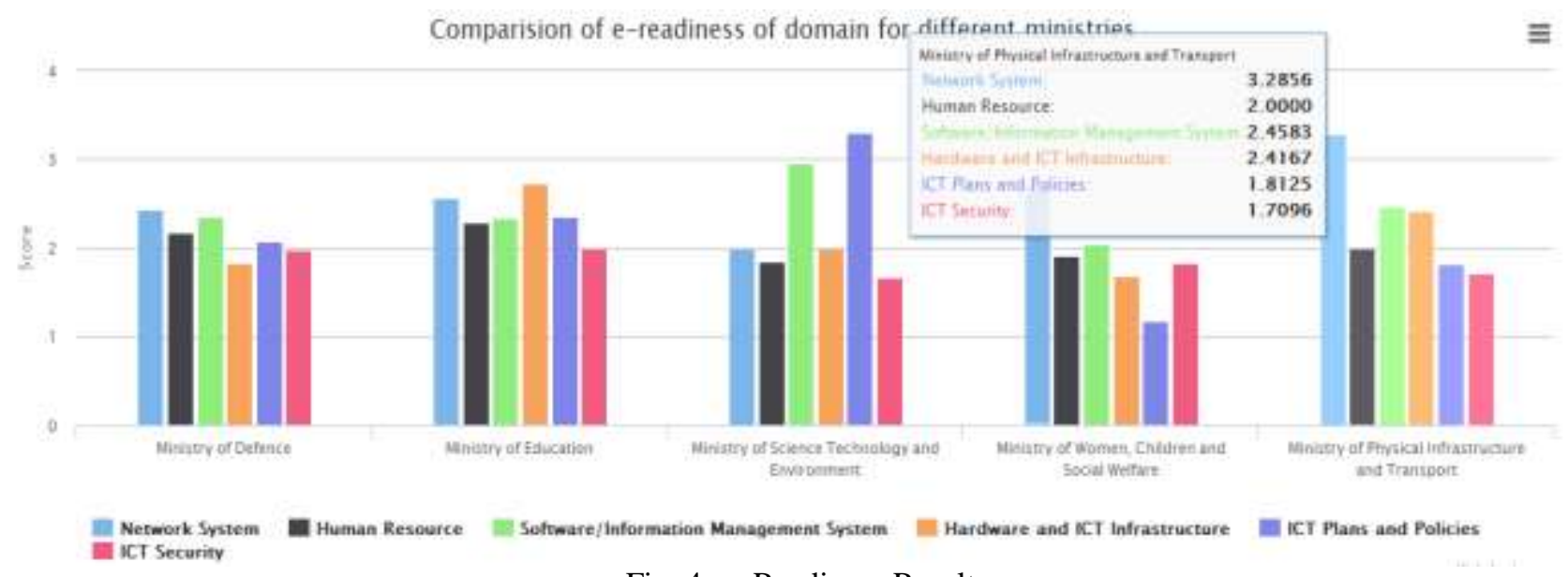

Fig. 4: e-Readiness Result

The results showed above clearly expresses the overall e-readiness level of each ministry. From the graph analytics below, it is clear that Ministry of Education has higher level of overall e-readiness and Ministry of Woman \& Social Welfare has lower e-readiness only having e-readiness level 1.93 out of 4 . Below table depicts e-readiness level in terms of Measure, Importance, Weight, and Relative Weight.

\begin{tabular}{l|l|l|l|}
\hline & Mriaty oi Defence & \\
\hline
\end{tabular}

\begin{tabular}{|c|c|c|c|c|}
\hline Dousin & Menuare: & lapportance & Weith & Relatuve Weida \\
\hline Network System & 2.55540000 & + & 0.1818 & 0464618179727 \\
\hline Hinan Renouce & 2.29124286 & 4 & 0,1818 & 0.416589609034 \\
\hline Software Lnformation Management System & 2.33485000 & 4 & 0.1818 & 0.424518179908 \\
\hline Hixdwere mod ICT Infrastoucture & 2.72119091 & 4 & 0.1818 & 0494761981410 \\
\hline ICT Plans and Poldides & 240859999 & 3 & 0.1364 & 0328036361398 \\
\hline \multirow[t]{2}{*}{ ICT Secunity } & 1.99765000 & 3 & 0.1364 & 0.272406817455 \\
\hline & \multicolumn{3}{|c|}{ E-Readiests } & 2490931128932 \\
\hline
\end{tabular}


Minstry del Science Technoiogr and Emismment *

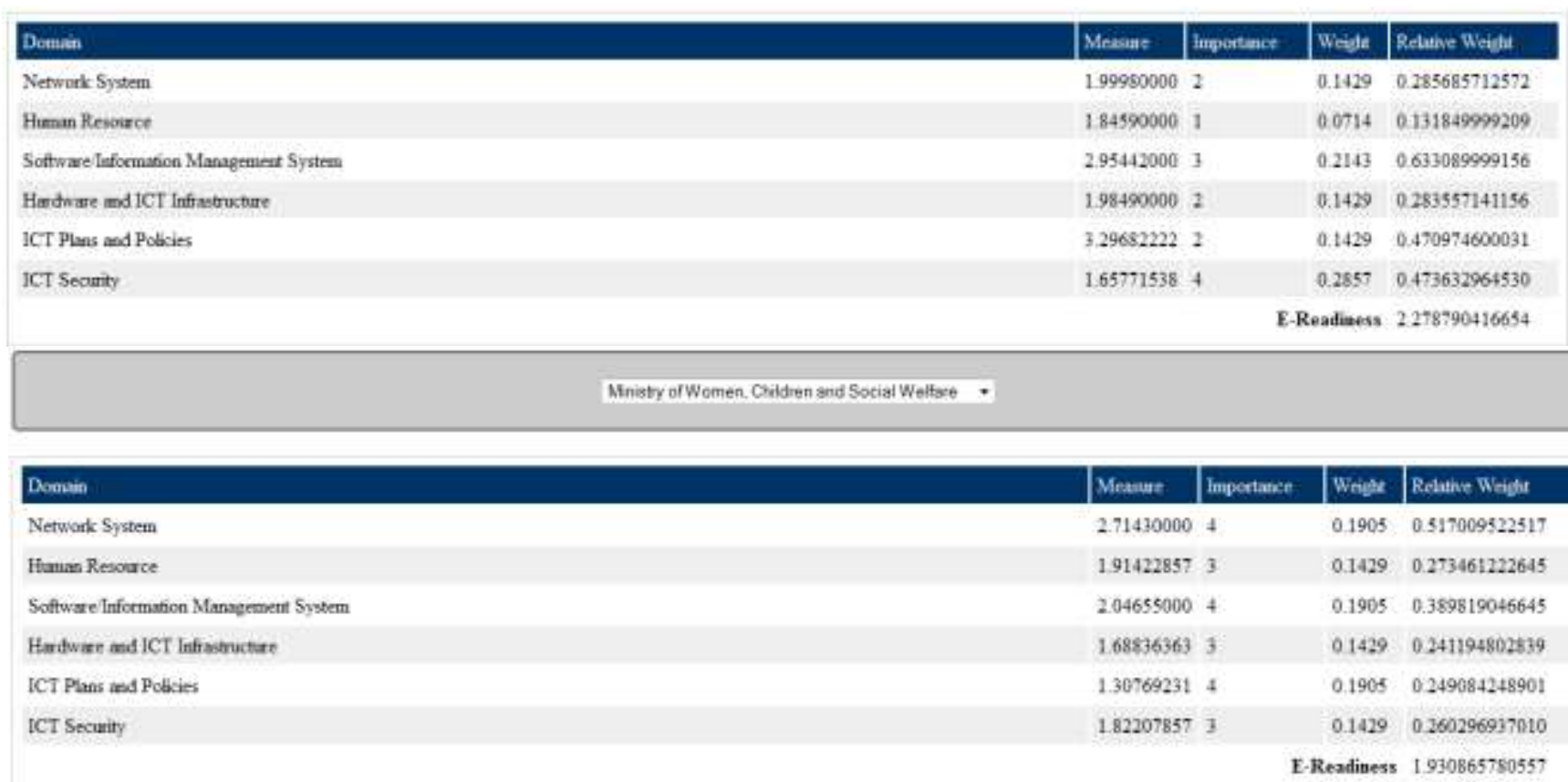

Ministry ol Physical intastucture and Transport -

\begin{tabular}{|c|c|c|c|c|}
\hline Demain & Mearaxe & Inportance & Weight & Relative Weight \\
\hline Network System & 3.28560000 & 4 & 0.1667 & 0.547599997810 \\
\hline Human Resocrce & 2.00000000 & 4 & 0,1667 & 0.333333332000 \\
\hline Sottwate / Irformation Mmapernert System & 2.45830000 & 4 & 0.1667 & 0.409716665028 \\
\hline Hardnate and ICT Inffastructare & 2.41666667 & 4 & 0.1667 & 0.402777776722 \\
\hline ICT Plans and Poticies & 1.81247500 & 4 & 0.1667 & 0.302079165458 \\
\hline ICT Securz̀y & 1.70957500 & 4 & 0.1667 & 0.284929165527 \\
\hline
\end{tabular}

E-Readiuess 2280436102545 .

\section{Acknowledgements}

We would like to express our sincere gratitude to Professor Dr. Subarna Shakya. We would also like to thank officers from Ministry of Defence, Ministry of Education, Ministry of Science and Technology and Environment, Ministry of Woman \& Children \& Social Welfare, Ministry of Physical Infrastructure and Transport of Nepal. Last but not least we would like to thank everyone who directly or indirectly helped us to make this research paper successful.

\section{References}

[1] Ndou, V. (. (2004). E-Government For Developing Countries: Opportunities and Challanges. EJISDC.

[2] Kungwannarongkun, P. C. (2011). ICT Readiness Assesment Model for Public and Private Organization in Developing Country. International Journal of Information adn Education Technology.

[3] Leila Beig, G. A. (2007). Adoption a Proper Tool For E-Readiness Assesment in Developing Countries. Journal of Knowledge Economy Management.

[4] Tung X. Bui, S. S. (2003). A framework for measuring national e-readiness. Int. J. Electronic Business Vol. 1. 
[5] Dada, D. (2006). E-Readiness For Developing Countries: Moving the Focus From the Environment to the Users. The Electronic Journal on Information Systems in Developing Countries .

[6] (Ahmed, 2006)

[7] AL-OSAIMI, K. I. (2007, june 5). Mathematical Models for E-Readiness Assessment of Organizations with Intranets.

[8] Alghamdi, I. A. (2011). E-Government Readiness Assessment for Government Organizations in developing Countries. www.ccsenet.org/cis. http://dx.doi.org/10.5539/cis.v4n3p3

[9] Purusottam Kharel, S. S. (2012). e-Government Implementation in Nepal: A Challanges. International Journal of Advanced Research in Computer Science and Software Engineering .

[10] Seyed Kamal Vaezi, H. S. (2009). Comparision of E-Readiness Assessment Models. Scientific Research and Essay .

[11] Soumitra Dutta, B. L. (2013). The Global Information Technology Report. World Economic Forum.

[12] Backus, M. E-Governance and Developing Countries.

[13] Islam, M. S. (2008). Towards a sustainable e-Participation implmentation model. European Journal of ePractice .

[14] Banepali.M.R (2013) . E-readiness of citizens and communities for their active engagement with local governments.

[15] http://mn.gov/mmb/mad/resources/survey/ (July,2014) 